\title{
The Case Study Method: A Step-by-step Approach for Analyzing Cases and Evaluating Students
}

\author{
Linda D. Lerner, (Email: llerner@tntech.edu), Tennessee Technological University \\ Linda H. Richey, (Email: lrichey@mtsu.edu), Middle Tennessee State University
}

\begin{abstract}
The case study is an excellent method for teaching and assessing students' knowledge and skills. Using two examples, we present a step-by-step approach for analyzing cases and evaluating students. The advantages and disadvantages of using cases are discussed and methods for identifying cases are presented.
\end{abstract}

\section{Introduction}

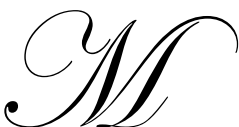

any of us in higher education, particularly those of us who teach in pre-professional programs, make a real effort to help our students move from an understanding of theory and concepts learned in the classroom to its practical application in the work place. Ultimately, if students are to be successful, they need to develop the appropriate skills as well as the confidence to apply those skills in real work situations. Through internships, practicum and other types of field work we attempt to prepare students for the kinds of professional experiences they will encounter at work. Even before they encounter those experiences, however, we can do much within the controlled environment of the classroom to help prepare them for the wide range of decision-making situations they will face.

Bloom's (1956) taxonomy of educational objectives, which provides a seminal perspective on student learning, continues to be useful to professors in higher education as they plan learning experiences for their students. The six basic categorical levels of educational objectives of this taxonomy are: knowledge, comprehension, application, analysis, synthesis, and evaluation. The directed analysis of well-written, comprehensive cases can help students achieve each of these objectives. Case analysis can help students develop their understanding of concepts and theory and how they are applied, refine their analytical and decision making skills, provide opportunities to synthesize learning in a variety of areas and ultimately build their confidence to deal with complex organizational situations. Given that there is often not a single way to deal with a problem or obvious paths to the best approaches or solutions, students must learn to analyze complex and dynamic situations, weigh their options and chart a course of action or response. While comfort will come with growing experience on the job, students need as much preparation and practice as possible before entering the work world.

The purpose of this paper is to provide direction to instructors who may want to use the case method. We describe a general approach to case analysis and two examples of how it can be applied. Each example describes how students are guided through a process which requires them to: analyze the information provided, identify the goals to be achieved, develop a plan to achieve the desired outcomes 
and work out an action or implementation plan to put their recommendations into place. Two sample cases from two different academic areas, business and education, are discussed to demonstrate how the approach can be applied and refined to achieve individual goals.

\section{A Step-By-Step Approach}

Our first example uses a fairly structured approach, building on basic decision-making models. Begin by having students briefly describe the basic facts of the case. Since a case can never provide all the information desired, it is helpful to ask students to define what they do know and identify any assumptions they are making based on their interpretation of the data. For example, a teacher may know certain things about a child he is assessing, but make certain assumptions about her home life based on her appearance or things the child or her parents say. Obviously students need to be able to defend their assumptions, and for students unable or unwilling to make any judgments because they "don't know everything" or "do not have all the facts," it is important to remind them that even in real situations it is not likely they will have all the information they desire.

The next step is to begin an analysis of the presenting data or situation. In business cases we often use what we refer to as a SWOT analysis to analyze the current situation. SWOT analysis, which stands for strengths, weaknesses, opportunities and threats, is a useful way to organize data that allows students to make meaningful observations and draw appropriate conclusions. Strengths are internal conditions, characteristics, resources or assets that give an individual, department, company or other entity an advantage or put them in a stronger position. A weakness, on the other hand, represents something that is lacking or a condition or characteristic that represents a liability or puts someone at a disadvantage. Opportunities and threats emanate from the external environment and represent opportunities or options available to the subject or conversely conditions or events that threaten the current or future position of the subject.

When the information is organized in this fashion, it is easier to move on to the next step which is to identify the issues or problems that must be addressed. The ultimate goal is to develop solutions that will deal with these issues and achieve the desired outcomes or results. It is helpful to frame each issue in the form of a question and important that the question not be stated as a solution to the problem. For example, "what should Company ABC do about declining product sales" as opposed to "should ABC sell its product in foreign markets?" Use of the second question may result in other options not being considered. It is also important at this point to urge students to identify all the issues, not just the obvious or presenting problem(s). When there are numerous issues it is helpful to have students prioritize them so they can deal with the most important ones first. For example, there may not be time or resources to deal with all the issues at once so ultimately students will have to decide what they will do first, second and so on.

Once the issues are identified, students must decide what to do about them. Here it is critical that they try to identify more than one option to deal with each issue. The tendency for all of us is to identify a single solution to a problem and then proceed with that. Encourage students to brainstorm all possible options and then weigh the pros and cons for the most viable options. In this way they can come up with the best possible solutions that meet most of their decision criteria or conditions.

When they have identified the best options or solutions, they can come up with a set of recommendations and a plan for putting them into action. The action plan serves as the blueprint for how to proceed. It is also helpful at this point to discuss contingencies, conditions or possible problems 
associated with implementation. It may also be useful to role play how some of their recommendations may actually be implemented. By going through a step-by-step approach students are more likely to identify the range of issues in the case and come up with the best solutions and recommendations. To illustrate how such an approach can be used in the classroom, a case is discussed that has been used by one of the authors to help students apply their knowledge to an actual work situation.

\section{Case 1}

The case concerns a serious problem facing the day care director of a large university-run day care center. The case is appropriate for any class dealing with management, human resource and ethical issues and has been used by one of the authors in a senior undergraduate management class. The details of the case will become apparent as we demonstrate how it could be used in the classroom following the approach described above. We know that the center, which serves approximately 60 children, 3-6 years of age, is part of a large state university. The center enjoys an excellent reputation and always has a lengthy waiting list for available spaces. There is a well-trained staff of professional and student workers who are very supportive of and care about each other. The center also has relationships with a variety of constituent groups who provide funding and other resources as well as state agencies that are responsible for licensing and some funding. The director, Susan, has just discovered that a part-time student worker, Bob, was arrested for selling drugs. This information has come from Margaret, an elderly part-time worker at the center, who is quite upset with Bob and sees him as a threat to the children. Margaret feels he must be removed from the center immediately. When Susan consults with her full-time staff, they see the situation a bit differently. They are concerned about Bob and willing to work with him, but they do not want to ignore Margaret's feelings. Bob appears for work later in the day but never says anything to Susan. When confronted by Susan, he breaks down and pleads with her to let him remain at the center. The case ends with Susan contemplating what to do about Bob.

Student discussion usually focuses on Bob with students taking positions on whether Bob should stay or not. Some will argue that he is a student who has made a mistake and should be given another chance. They also point out that he is innocent until proven guilty. Others argue that he is guilty since he has as much as admitted it to Susan and should under no circumstances be permitted to work with the children. Without using a more focused or structured approach, students may or may not identify all the issues Susan needs to consider as she comes up with a workable plan for dealing with Bob.

Once the facts of the case are described, a SWOT analysis can be used to analyze the situation. Although this is a short case, a number of strengths can be identified. They include: a good reputation, various funding sources including state funding, a competent staff, more clients than can be accommodated, access to University resources and good relations with community and parents. Few weaknesses are apparent from the case although the division of the staff over Bob's fate is a potential weakness. There are a number of threats. If the news of Bob's arrest becomes widespread, it could hurt the center's reputation with its various constituency groups and potentially affect funding if not dealt with appropriately. There is also the potential threat to the staff's harmony and the threat to the trust and wellbeing of the parents if they find out what is going on. An opportunity, however, also exists to help Bob.

Given the SWOT analysis, students should be prepared to identify the issues. While the most apparent issue concerns what to do about Bob, there are other issues. Susan must decide how to deal with the differences between Margaret and the other staff members and whether and what to tell parents. Once the issues are identified, students generate options for dealing with each issue. With regard to Bob, the obvious options are removing him from the center or letting him continue working until his trial. When 
pushed to come up with other options someone will often come up with the idea of letting Bob continue to work at the center but not in any capacity that brings him in contact with children. The pros and cons of each can then be discussed. Letting him work there allows the staff to demonstrate their support of Bob. Bob has been a good worker and many parents like having males work at the center since many of the children are in one parent families with an absent father. The negatives include potential threats to the center if he does go to trial and is convicted. Removing Bob has the benefit of eliminating those potential threats and eases the concerns of Margaret. On the negative side, there is concern for Bob and whether he might try to harm himself. Some students will also bring up the legal issue of whether Bob can be fired before his trial. Since he is a student worker, his removal is not likely to be a problem, although he could be placed on leave and still be paid. The third option would allow the staff to still have contact with and be able to support Bob but without any direct threat to the children. The negative is that Bob would still be at the center and could potentially present a threat if he is tried and convicted. As the students discuss in some depth the pros and cons, it will become easier for them to decide on a solution and develop their recommendations.

Again, the same approach should be utilized with each issue. The students can discuss the pros and cons of dealing with Margaret, for example. Interestingly, virtually all students in discussions I have had completely dismiss Margaret's concerns. They assume she has no standing with the other staff members, which is an assumption they cannot make. They also assume it is inevitable that parents will find out about Bob and on that basis must tell them. Since that never occurred in the actual situation on which the case is based, that is another erroneous assumption. Again the discussion should proceed on the basis of the pros and cons of the various options. If they believe parents should be told, they should base their arguments on a belief that it is the right thing to do. Once the options are fully discussed and a plan of action developed, it will be beneficial to discuss implementation of the plan. For example, if the decision is made to remove Bob, how should Susan tell him? What can she do to help him? It might be helpful at this point to do a role play. In a similar fashion, if a decision is made to inform parents, how should they go about informing them? By the time they are finished, students have a good idea of how they would proceed. Since this case is based on an actual situation and was written by one of the authors, students often ask "what really happened?" While it is always interesting to know the actual outcomes, it is important to stress that what was done may not necessarily be the best or the only response to the issues in the case. That, of course, applies to all cases. As described above, this approach is relatively structured, but can be adapted to other situations and to meet other objectives.

\section{Case 2}

In our second example, we describe how the case method is used in an early childhood education program to help train and evaluate students who are preparing for student teaching. Here the focus is on the individual student who is preparing for his/her first student teaching experience. The use of a case study approach for early childhood pre-service teachers has at its foundation the same educational objectives described above: knowledge, comprehension, application, analysis, synthesis, and evaluation (Bloom, 1956). Students' coursework and field experiences reflect the increasing complexity of these objectives.

Lower division courses in early childhood education help to broaden and deepen students' knowledge and comprehension of educational pedagogy. The ability to implement developmentally appropriate and effective practices, to have a multicultural perspective, and to provide education inclusively to all children grows and develops with students' exposure to these principles and practices in their coursework. With field experiences students are able to implement these principles and practices, 
thus demonstrating their comprehension. Through analysis of the various situations they encounter in their observational and tutoring experiences, students are able to gain more skill and actually implement under close supervision specific instructional plans.

As students move into their upper division coursework, they are given more supervised responsibility to analyze educational situations and develop instructional and child guidance plans in an ethical manner. In addition students' work continues to be grounded in the context of child development and growth principles and with a family partnership perspective. Students are encouraged to be creative in developing these plans that may be related to specific content, such as mathematics, reading, and science.

As students reach the end of their formal coursework and field experiences in early childhood education, they are required to complete a case study as a means of evaluating their ability to synthesize their pre-professional knowledge and skills. This case study is completed at the end of the semester prior to their student teaching experience. Although used as an evaluation tool for the assessment of students' ability to successfully plan and implement a unit of study for young children, it is also a structured experience to help prepare students for a more involved and complex application of their knowledge and skills during their student teaching semester. Completing a case study allows students to create coordinated learning experiences for a diverse population of children. During the student teaching experience students will not only create those learning experiences, but implement and evaluate them as well.

Students are given a case study of a large urban public school first grade classroom. Included in this case are the following: a description of the teacher, including information about her desire to teach and her education; a brief physical description of the classroom, including the furniture, equipment, materials, and space; potential obstacles to successfully implementing an appropriate program, including the number of children, lack of supplies, conflict with colleagues with regard to teaching styles, and school politics; and, most importantly perhaps, the positive element that may support her success--a teacher who will mentor her.

Very specific information about individual children in the teacher's class is given. The class is a large one containing 31 children. Some of the children have very specific special needs, such as having a limited vocabulary, having a very short attention span, being easily distracted, and having difficulty following directions. In addition, two of the children are English language learners. Most of the children in the class are developing typically.

In addition to the above information, students are given a summary of some of the perceptions and beliefs that are current in education, especially public education, and that are being implemented at her present school assignment. They are also given a brief statement of this teacher's first observation and evaluation by her supervisor. To make the experience more interesting, a realistic description of the children's behavior and general needs are provided.

Students are expected to design a program of study that uses developmentally appropriate and effective practices with young children. In the college classroom these students have learned what best practice is. Now they must determine how a professional applies what was learned to a real learning community. Students also understand there is a code of ethics to guide their decisions. At the same time there are expectations and demands made of them by their first grade students, the family members of those students, school personnel (including colleagues and supervisors), and community members. 
A problem-solving approach must be used. As in the first example, this case study requires that students identify the task to be accomplished, analyze the information given, consider the various options available to successfully accomplish the task, think about the desired outcomes, and determine the means of achieving those outcomes. Very specific goals, objectives, and assessment plans must be stated. Goals and objectives based on State education learning goals and the individual and group needs of the first grade children must be developed.

No specific model of a finished project is provided to the early childhood education students. They are encouraged to think about what the challenges are and how best to meet them. It is then suggested that they brainstorm ideas about how to actually plan a six-week curriculum that reflects inclusion, multicultural education, and developmentally appropriate and effective practice. Specific content in math and science must be included and themes must be used in addition to at least one first grade student project.

Students are encouraged to reflect first and then write. Coursework and field experiences have prepared them. Student jottings of possible courses of action are helpful. But, students must first think through the process. Students are supported through this process individually by professors. As ideas emerge, they are encouraged to conference with their professors. Eventually a structure is suggested to the students about how best to visually represent the information and present the completed product, a sixweek curriculum plan, including a rationale for the decisions made.

\section{Advantages of Casework}

In addition to using the case study as a training tool, there are advantages to using it as an evaluation instrument. In the preceding example, the professor is able to get a good picture of each student's abilities, including strengths and areas that need to be strengthened. This is especially important when a student exhibits a lack of basic knowledge and skills necessary to be successful during the student teaching experience. Although by this time students should have exhibited basic pre-service teaching competence, it may be necessary for a student to be involved in remediation. The product produced as a result of the work invested in a case study can document student abilities. Although the case described in the first example is not really comprehensive enough to serve as an evaluation instrument, more complex cases can be used to test students' learning in many academic areas.

It should also be noted that if the case study is used as an assessment tool at the end of the semester, it may result in an exercise that is evaluated by the professor, but not discussed with the student because of end of semester scheduling and responsibilities. Planning to have this exercise before the end of the semester, even if used as an assessment tool, will allow for more discussion and student reflection both individually and in a group and will ultimately be more beneficial to the student.

Using the case study as a precursor to a student teaching experience, practicum, internship or any real work experience provides many benefits for the student. In our second example, students are required to take a "real" situation, that is a learning community of first graders, and develop an instructional plan. The student is supported in the decisions he or she makes through discussions with classmates and professors during the case study process and through the utilization of additional resources, including textbooks, professional journals, curriculum guides, and the Internet. In our initial example, students are able to assume the role of an actual administrator who is dealing with a real problem and to consider how they would handle it. There are many ways this type of experience can be accomplished through the use of cases. 
The case study process, however, is not without its disadvantages. In addition to the possible lack of follow-up to an end-of-semester case study, students may also experience varying amounts of frustration. They may initially be uncomfortable with the openness and flexibility of the case study process. Given the educational choices to be made and wanting to make the best decisions, students may be hesitant at the beginning of this creative, problem-solving process. Wanting to provide the "correct" answer may well drive the case study process for students until they realize that there is not one correct answer. Once they are reassured that there are many appropriate ways to meet the requirements of the case study, they can begin to reflect upon the situation and productively tackle the issues. Students, particularly those working individually, will need encouragement and support. For those working in groups there is the added benefit of many perspectives, but also the frustration of potential disagreement about the best course of action. In both situations, providing students with the tools of case analysis and appropriate support can mean the difference between success and failure.

\section{Conclusion}

For the instructor interested in using the case approach, it is important to note that there are many sources for obtaining cases. Written, published cases are available in many texts. Instructors should also consider writing their own cases based on their own experiences or from secondary sources. These can be full-length cases or vignettes that students use for discussion or as experiential exercises. Cases can be developed from newspaper articles and reports. Movies and videos are another source of case material. In business courses, students often develop their own cases from a wide range of secondary sources. The use of primary sources is another way to develop cases. Individuals from the chosen field can be invited into the classroom to share problems that students are asked to help solve or instructors may identify community organizations with which students can work.

In summary, cases can be an excellent vehicle for reaching educational objectives. Cases are interesting to students because they deal with "real world" and "real work" situations, providing the basis for stimulating discussions and assignments. They can be used as the basis for class discussion as well as individual and group projects and reports. They are appropriate for both long and short-term assignments and are an excellent way to evaluate students. Cases are used in many academic areas as part of a capstone experience, providing students with a means for synthesizing and integrating much of what they have learned. As an educational tool, the case study approach and the process is an excellent way to prepare students for what lies ahead.

\section{References}

Bloom, B. S. (Ed.). (1956). Taxonomy of educational objectives: The classification of educational goals. New York: David McKay. 
Notes 